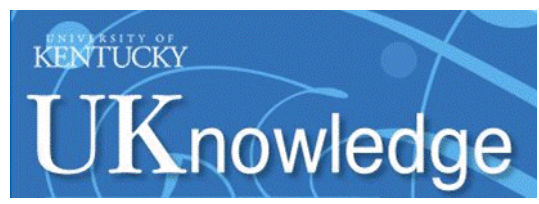

University of Kentucky

UKnowledge

\title{
Curbing the DUI Offender's Self-Efficacy to Drink and Drive: A Laboratory Study
}

Walter Roberts

Yale University

Mark T. Fillmore

University of Kentucky, fillmore@uky.edu

Follow this and additional works at: https://uknowledge.uky.edu/psychology_facpub

Part of the Behavior and Behavior Mechanisms Commons, Psychology Commons, and the Substance Abuse and Addiction Commons

Right click to open a feedback form in a new tab to let us know how this document benefits you.

\section{Repository Citation}

Roberts, Walter and Fillmore, Mark T., "Curbing the DUI Offender's Self-Efficacy to Drink and Drive: A Laboratory Study" (2017). Psychology Faculty Publications. 174.

https://uknowledge.uky.edu/psychology_facpub/174

This Article is brought to you for free and open access by the Psychology at UKnowledge. It has been accepted for inclusion in Psychology Faculty Publications by an authorized administrator of UKnowledge. For more information, please contact UKnowledge@lsv.uky.edu. 


\section{Curbing the DUI Offender's Self-Efficacy to Drink and Drive: A Laboratory Study \\ Digital Object Identifier (DOI) \\ https://doi.org/10.1016/j.drugalcdep.2016.12.005}

\section{Notes/Citation Information}

Published in Drug and Alcohol Dependence, v. 172, p. 73-79.

(๖ 2017 Elsevier B.V. All rights reserved.

This manuscript version is made available under the CC-BY-NC-ND 4.0 license

https://creativecommons.org/licenses/by-nc-nd/4.0/.

The document available for download is the author's post-peer-review final draft of the article. 


\title{
Curbing the DUI offender's self-efficacy to drink and drive: A laboratory study
}

\author{
Walter Roberts ${ }^{1}$ and Mark T. Fillmore ${ }^{2,3}$ \\ ${ }^{1}$ Yale School of Medicine, Department of Psychiatry, 2 Church Street South, Suite 109, New \\ Haven CT, 06519 \\ 2University of Kentucky, Department of Psychology, 115 Kastle Hall, University of Kentucky, \\ Lexington KY, 40506
}

\begin{abstract}
Background-People arrested for driving under the influence of alcohol (DUI) are at high risk to reoffend. One reason for this high rate of recidivism among DUI offenders is that these individuals systematically underestimate the degree to which alcohol impairs their ability to drive. This study compared perceived and objective driving ability following alcohol and performance feedback in drivers with and without a history of DUI.
\end{abstract}

Method-Adult drivers with $(\mathrm{n}=20)$ and without $(\mathrm{n}=20)$ a history of DUI arrest attended two dose challenge sessions where they received $0.64 \mathrm{~g} / \mathrm{kg}$ alcohol or placebo, completed a simulated driving task, and provided measures of subjective impairment. They attended a third retesting session where they received feedback that they were impaired by alcohol. They received $0.64 \mathrm{~g} / \mathrm{kg}$ alcohol and their objective and perceived driving ability was retested.

Results-Both groups showed significant impairment of driving performance following 0.64 $\mathrm{g} / \mathrm{kg}$ alcohol compared to placebo. DUI offenders rated themselves as less impaired than controls. After performance feedback, self-reported impairment during the alcohol retest increased for DUI offenders but not for controls. There was no effect of performance feedback on objective driving ability.

Conclusions-These results support the notion that under alcohol DUI offenders characteristically perceive themselves as better able to drive than non-offenders. These perceptions can be tempered by performance feedback. To the extent that perceived ability to drive safely after

${ }^{3}$ Corresponding author: Telephone: (859) 257-4728, Fax: (859) 323-1979, fillmore@uky.edu.

Publisher's Disclaimer: This is a PDF file of an unedited manuscript that has been accepted for publication. As a service to our customers we are providing this early version of the manuscript. The manuscript will undergo copyediting, typesetting, and review of the resulting proof before it is published in its final citable form. Please note that during the production process errors may be discovered which could affect the content, and all legal disclaimers that apply to the journal pertain.

Author Disclosures

Conflict of interest

No conflict to declare.

Contributors

All authors were involved in conceptualizing the study, designing the experiment, analyzing and interpreting the data. W. Roberts drafted the manuscript and M. T. Fillmore provided critical revisions. All authors approved the final version of the manuscript for submission. 
drinking contributes to DUI and its recidivism, feedback geared towards lowering this self-efficacy could reduce willingness to engage in this behavior.

\section{Keywords}

DUI; driving; subjective impairment; alcohol; self-efficacy

\section{Introduction}

Approximately one-third of the people who are arrested for driving under the influence of alcohol (DUI) in the United States are repeat offenders (NHTSA, 2015). These high rates of recidivism cannot be entirely attributed to alcohol dependence (Shaffer et al., 2007); instead, there appear to be enduring characteristics of DUI offenders maintaining this pattern of maladaptive decision-making. Drawing on self-efficacy theory (Bandura, 1977), we propose here that DUI offenders persist in driving while impaired because they systematically underestimate the degree to which alcohol impairs their ability to drive. We also propose that this underestimation of impairment can be corrected during later drinking episodes using personalized driver performance feedback that challenges such beliefs.

Motivated behavior is guided by expectations of how one will perform in a given situation. This basic premise is the foundation of self-efficacy theory (Bandura, 1977), which posits that individuals' initiation or persistence in an action are determined primarily by their judgements and expectations concerning their capacity to cope with the demands and challenges of that situation (Maddux, 1995). High self-efficacy also may lead to problematic behaviors, particularly when expectations of one's ability exceed the individual's actual ability (Bandura, 1982). People avoid actions that may result in harm if they do not believe that they can safely cope with the demands of the situations. Prior research on the causes of alcohol impaired driving finds that this decision is associated with perceived impairment such that drinkers who perceive that they are able to drive are likely to do so (Quinn and Fromme, 2012). Unfortunately, there is poor correspondence between one's perceived and objective alcohol impairment (Aston and Liguori, 2013). This incongruence may be stronger among DUI offenders due to their heightened levels of impulsivity (Donovan et al., 1990), which is associated with overestimation of ability level (de Bruijn et al., 2006; Shiels and Hawk, 2010).

Along these lines, we have conducted studies to compare objective and perceived behavioral impairment in response to a dose of alcohol in impulsive groups. One line of studies found that a clinical group characterized by impulsivity (i.e., adults with ADHD), rated themselves as less impaired by alcohol than controls despite being equally or more impaired than controls (Roberts et al., 2013; Weafer et al., 2008; Weafer et al., 2009). Another study found that DUI offenders reported regaining their driving ability more quickly following an acute dose of alcohol compared to non-offending controls despite their being no group differences in alcohol elimination rates (Van Dyke and Fillmore, 2014b). This is problematic because drivers who underestimate levels of impairment tend take more risks when driving. Our group found a relation between estimated breath alcohol concentration $(\mathrm{BrAC})$ and risky 
driving such that drivers who estimated having lower BrACs drove in a riskier fashion (Laude and Fillmore, 2016).

If DUI offenders are prone to underestimating their level of impairment, then challenging their underestimation with feedback (i.e., information that their driving was highly impaired by alcohol) should produce a more adaptive perception of their abilities. People estimate their ability to perform a task based on past experiences (Bandura, 1977). For impaired driving, DUI offenders likely consider past referential experiences to inform judgements of their ability to drive after drinking. Research on individual instances of driving after drinking show that a single episode of this behavior is unlikely to result in any appreciable negative outcome (Voas and Fell, 2013). It is estimated that for every DUI arrest that occurs, the driver engages in 200 episodes of driving after drinking (Beitel et al., 2000). Thus, in the vast majority of these instances, there is no significant negative outcome for the driver. The experience of repeated episodes in which driving after drinking yields no adverse consequence could heighten one's self-efficacy to drive safely after drinking and without risk of arrest. As such, heightened self-efficacy could eventually play an important role in maintaining and increasing the frequency of driving while intoxicated, calling attention to its importance as a target for intervention. One method to reduce the likelihood of engaging in specific behaviors is to lower one's self-efficacy to successfully execute the behavior (Bandura and Locke, 2003). One strategy to lower self-efficacy is to provide information, such as negative performance feedback, to indicate a lack of ability to execute the task. Such feedback should reduce an individual's willingness to engage in that behavior in the future.

The current study examined simulated driving performance and subjective perceptions of one's driving ability following $0.64 \mathrm{~g} / \mathrm{kg}$ alcohol (approximate peak $\mathrm{BrAC}=80 \mathrm{mg} / 100 \mathrm{ml}$ ) and placebo in a group of DUI offenders and control drivers. The study also tested the degree to which intoxicated drivers' perception of their driving skill would be lowered after receiving feedback showing that alcohol impairs their driving ability. We reasoned that if DUI offenders overestimated their abilities due to failure to perceive alcohol impairment, then providing information indicating that alcohol impaired their driving performance should reduce their overestimation of ability. We predicted that alcohol would impair driving performance in both groups. Regarding perceived levels of impairment, we predicted that, under alcohol, DUI offenders would report greater ability to drive than controls, and that such overestimation of ability would be reduced after DUI offenders received performance feedback.

\section{Method}

\subsection{Participants}

Participants were 20 adult DUI offenders and 20 adult drivers with no prior DUI conviction. We expected to recruit more male DUI offenders than female offenders because more males are arrested for DUI (U.S. DOJ, 2005), so we over recruited males into the control group. Our DUI group included 14 men and 6 women, and our control group included 13 men and 7 women. DUI offenders had at least one alcohol-related DUI conviction in the past five years, whereas control participants had no prior DUI convictions or license revocations. Interested individuals called the laboratory and underwent a telephone screening during 
which information on demographics, drinking habits, drug use, and physical and mental health was gathered. Individuals reporting any psychiatric disorder, CNS injury, or head trauma did not participate, nor did those reporting dependence on illicit drugs. After being recruited, participants were informed that the study was intended to examine the effects of different doses of alcohol on simulated driving performance as well as other aspects of cognitive functioning.

All volunteers were current consumers of alcohol but were excluded if they reported past or current criteria for alcohol tolerance and withdrawal as determined by the substance use disorder module of the Structured Clinical Interview for DSM-IV (SCID-I; First et al., 2002). All volunteers had to hold a driver's license for the past three years and drove at least once each week. No participant reported using any psychoactive prescription medication. Illicit drug use was assessed by means of urine analysis (ICUP Drug Screen, Instant Technologies). Positive screens for drugs other than tetrahydrocannabinol (THC) during a dose challenge session resulted in rescheduling of that session. Those whose urine tested positive for THC were allowed to continue the session only if they abstained from using THC for at least 24 hours prior to the sessions. No female volunteers who were pregnant or breast-feeding participated in the research (Icon $25 \mathrm{Hcg}$ Urine test, Beckman Coulter). The research was approved by the University of Kentucky Medical Institutional Review Board. Participants were compensated $\$ 130$.

\subsection{Materials and Measures}

2.2.1 Driving simulation-A simulated driving task was used to measure driving ability (STISIM Drive, Systems Technology Inc., Hawthorne, CA). This apparatus has been used in prior studies on alcohol-impaired driving (Harrison and Fillmore, 2005). It included footpedals and a steering wheel. Participants were instructed to maintain a speed of $55 \mathrm{mph}$ and remain in the middle of the right lane during a 5-mile drive on a meandering rural road and required 10 minutes to complete.

Criterion measures were standard indicators of driving performance, including lane position standard deviation (LPSD), average speed, standard deviation of speed (speed SD), number of collisions, and number of times crossing the outer edge or center line of the roadway. To calculate LPSD, we measured within-lane position continuously throughout a test. Withinlane position was sampled at each foot of distance during the entire drive, and these data were used on each test to calculate an average within-lane position for each participant. Within-lane deviation was calculated by averaging each driver's deviation from his or her mean position at each foot of the driving test. The within-lane deviation measure is an indicator of the degree of adjustment that a driver implements to maintain a desired position within the lane. LPSD is a sensitive indicator of alcohol impairment of driving ability (Fillmore et al., 2008).

Speed deviation is an indicator of the degree of adjustment that a driver implements to maintain a desired speed. Greater speed deviation indicates greater difficulty in maintaining a constant speed and is sensitive to the impairing effects of alcohol (Marczinski et al., 2008). Line crossings (number of times that the driver crossed over the center line into the 
oncoming traffic lane or crossed into the shoulder) and collisions (number of times the driver collided with the edge of the road or another vehicle) were also recorded.

2.2.2. Barrett Impulsivity Scale (BIS; Patton et al., 1995)—This 30 -item questionnaire measured impulsiveness using items such as "I act on impulse" and "I consider myself always careful." This measure was included to better describe our sample by confirming that DUI offenders reported higher levels of impulsivity, consistent with prior research.

2.2.3. Assessment of Drinking Habits—The Timeline Follow_back (TLFB; Sobell and Sobell, 1992) assessed daily patterns of alcohol consumption over the past 90 days using a structured calendar. Measures included: total drinks (total number of drinks consumed), drunk days (total number of days that participants reported feeling drunk), drinking days (total number of days that alcohol was consumed, and binge days (total number of days characterized in which alcohol use was estimated to yield a BrAC of $80 \mathrm{mg} / 100 \mathrm{ml}$ or higher [National Institute on Alcohol Abuse and Alcoholism, 2004]). Estimated BrAC for each drinking day was calculated using the formula developed by Watson and colleagues (1981). This formula accounted for differences in absolute alcohol volume that exist between different types of alcohol beverages (i.e., beer, wine, spirits). The Personal Drinking Habits Questionnaire (PDHQ; Vogel-Sprott, 1992) was used to meausre quantity and frequency of typical drinking episodes and number of months using alcohol.

2.2.4 Perceived Driving Ability and Subjective Intoxication-Participants rated the degree to which their driving ability was impaired by the alcohol to measure their perceived impairment. They also rated how intoxicated they felt (subjective intoxication). Both ratings used 100-mm visual analog scales (VAS) ranging from $0 \mathrm{~mm}$ (not at all) to $100 \mathrm{~mm}$ (very much). Perceived driving ability was measured to test the hypothesis that DUI offenders perceived less alcohol impairment than controls. Subjective intoxication differs from perceived impairment in that intoxication is based on interoceptive cues of the drug's effects and perceived impairment reflects perception of the ability to execute a specific behavior under the drug. Although DUI offenders were predicted to perceive less impairment than controls, they might not differ from controls in their level of subjective intoxication.

\subsection{Procedure}

2.3.1. Familiarization session-Volunteers provided informed consent and underwent screening during a familiarization session. They completed the simulated driving task once in order to familiarize them with operating the driving simulator and minimize practice effects. They also completed a series of questionnaire and behavioral measures, including the Kaufman Brief Intelligence Test $-2^{\text {nd }}$ Edition to measure estimated IQ (Kaufman and Kaufman, 2004).

2.3.2. Dose-challenge sessions-During the first two dose-challenge sessions, participants received placebo and $0.64 \mathrm{~g} / \mathrm{kg}$ alcohol in a counterbalanced order to determine objective and perceived alcohol impairment of driving ability. Participants were blind to beverage condition during each dose-challenge session. They returned for a third session 
during which they received sham performance feedback indicating that their driving performance was highly impaired by alcohol during the previous sessions. They were then retested under a subsequent $0.64 \mathrm{~g} / \mathrm{kg}$ alcohol dose. All tasks were administered in a fixed order. Following alcohol administration sessions, participants relaxed in a laboratory area and their $\mathrm{BrAC}$ was measured in 20 minute intervals. They were allowed to leave the laboratory when they reached $20 \mathrm{mg} / 100 \mathrm{~mL}$ and provided with transportation home as needed. All dose sessions started between 10:00am and 6:00pm and lasted no longer than six hours.

2.3.2.1. Alcohol administration sessions: During each dose-challenge session, volunteers first completed a pre-session checklist to ensure compliance with the study requirements. They were instructed to abstain from consuming alcohol 24 hours before each session. Expired air samples were taken at the beginning of the session to verify zero BrAC (Intoxilyzer, Model 400; CMI, Owensboro, KY). During this session, participants were reminded that the experiment was intended to examine their driving performance under different doses of alcohol.

The alcohol beverage was served as one-part alcohol and three-parts carbonated mix divided equally into two glasses. The placebo consisted of four-parts carbonated mix that matched the volume of the $0.64 \mathrm{~g} / \mathrm{kg}$ dose. Five milliliters of alcohol were floated on the top of each placebo glass, and the glasses were sprayed with an alcohol mist that resembles condensation and provides an alcohol odor. Participants drank both beverages within six minutes. Thirty minutes after drinking, drivers completed the simulated driving task and subjective measures were collected 55 minutes after drinking. BrAC was measured at 25, 40, $50,65,85$, and 105 minutes post-dose administration.

2.3.2.2. 0.64 $\mathrm{g} / \mathrm{kg}$ alcohol retest session: The purpose of the retest session was to test whether receiving performance feedback indicating driving ability was impaired by alcohol increase drivers' perceived levels of impairment during a subsequent dose of alcohol. Participants were told that they would receive a dose of alcohol and again complete the simulated driving task. Instructions were identical to those used during the prior alcohol administration sessions. The structure of the $0.64 \mathrm{~g} / \mathrm{kg}$ alcohol retesting session was identical to the initial alcohol session except that at the beginning of this session drivers received feedback indicating that their performance was highly impaired during the prior alcohol session. At the beginning of the retest session, the experimenter invited each driver to look at a graph that ostensibly illustrated his/her severe level of driving impairment following alcohol compared to their driving performance during the familiarization session. The data illustrated in the graph were fabricated to illustrate a pronounced impairing effect of alcohol on driving performance. All participants viewed the same graph. This method of providing performance feedback to alter behavior under alcohol is similar to that used in prior research (Fillmore and Vogel-Sprott, 1996).

\subsection{Data Analyses}

Group differences in demographics, drinking habits, and driving history were analyzed using independent samples $t$ tests. BrACs during the active dose conditions were analyzed by a 2 
group (DUI versus control) $\times 2$ condition $(0.64 \mathrm{~g} / \mathrm{kg}$ alcohol versus $0.64 \mathrm{~g} / \mathrm{kg}$ alcohol retest) $\times 6$ time $(25,40,50,65,85$, versus 105 minutes past dose) mixed-design ANOVA.

Primary outcome variables, including driving performance variables, perceived driving ability, and subjective intoxication, were analyzed using 2 (group: Controls vs. DUI Offenders) $\times 3$ (condition: placebo, $0.64 \mathrm{~g} / \mathrm{kg}$ alcohol, $0.64 \mathrm{~g} / \mathrm{kg}$ alcohol retest) mixeddesign analysis of variance (ANOVA). We used a priori $t$ tests to probe any significant main effects of condition or group $\times$ condition interactions. If there only was a main effect of condition, we collapsed across group and made comparisons across condition. If there was a group $\times$ condition interaction, we compared performance between group within each condition.

\section{Results}

\subsection{Demographics, Drinking Habits, and Driving History}

Descriptive statistics and group comparisons on demographics, drinking habits, and driving history are presented in Table 1. There was no significant group difference in any demographic or alcohol use variable. However, DUI offenders reported significantly more alcohol-related problems on both the abuse and dependence modules of the SCID-I. DUI offenders also reported higher levels of impulsivity on the BIS. DUI offenders reported receiving more moving vehicle citations than did controls, but there was no significant difference in the reported number of collisions. Seventeen DUI offenders reported one past DUI conviction and three reported two past DUI convictions. The mean amount of time between their most recent DUI and their participation in the study was 19.0 months $(\mathrm{SD}=$ 15.1 months, range: 1 month - 46 months).

\subsection{Breath Alcohol Concentrations}

BrACs are graphed in Figure 1. This figure shows that BrACs rose to a peak of approximately $80 \mathrm{mg} / 100 \mathrm{ml}$ at 65 minutes following alcohol administration. The mixeddesign ANOVA found a main effect of time, $F(1,38)=35.11, \mathrm{p}<.001, \eta_{\mathrm{p}}{ }^{2}=.48$, due to the rise and fall of the BrAC curve over the course of the session. There was no other significant main effect or interaction effect ( $\mathrm{ps}>.250$ ).

\subsection{Driving Performance}

Driving performance on the simulated driving task is reported in Table 2. As seen in this table, there was no significant main effect of group or group $\times$ condition interaction. There were, however, significant main effects of condition on LPSD and line crossings. Table 2 shows that both groups had higher LPSD under alcohol with and without performance feedback compared to placebo. A priori t tests found that compared to placebo, drivers had higher LPSD during the first alcohol session, $\mathrm{t}(38)=3.29, \mathrm{p}=.002, \mathrm{~d}=0.57$, and the retest session, $\mathrm{t}(38)=3.65, \mathrm{p}<.001, \mathrm{~d}=0.60$. There was no significant difference in LPSD between the first and retest alcohol sessions, $\mathrm{t}(38)=0.72, \mathrm{p}>.250, \mathrm{~d}=0.11$. A priori t tests on line crossings found that compared to placebo, participants made more line crossings during the first alcohol session, $\mathrm{t}(38)=3.32, \mathrm{p}=.002, \mathrm{~d}=0.61$, and the alcohol retest 
session, $\mathrm{t}(38)=3.37, \mathrm{p}=.002, \mathrm{~d}=0.59$. There was no significant difference in line crossings between the alcohol and the alcohol retest, $\mathrm{t}(38)=0.40, \mathrm{p}>.250, \mathrm{~d}=0.06$.

\subsection{Perceived Driving Ability}

Participants' ratings of perceived ability to drive are graphed in Figure 2. There was a significant main effect of condition, $F(2,76)=139.93, \mathrm{p}<.001, \eta_{\mathrm{p}}{ }^{2}=.79$, and group $\times$ condition interaction, $F(2,76)=5.22, \mathrm{p}=.008, \eta_{\mathrm{p}}{ }^{2}=.012$. As seen in Figure 2, this interaction occurred because DUI offenders reported greater driving ability during the first alcohol session than did controls, but during the alcohol retest session their perception of greater ability was no longer evident. The a priori $t$ tests found that DUI offenders reported greater driving ability than controls during the first alcohol session, $\mathrm{t}(38)=2.89, \mathrm{p}=.006, \mathrm{~d}$ $=0.94$; however, during the alcohol retest their perceived ability did not differ from controls, $\mathrm{t}(38)=1.17, \mathrm{p}=.249, \mathrm{~d}=0.38$. No group difference in reported driving ability was observed following placebo, $\mathrm{t}(38)=0.81, \mathrm{p}>.250, \mathrm{~d}=0.26$.

\subsection{Subjective Intoxication}

Ratings of intoxication also are presented in Figure 2. There was a significant main effect of condition, $\mathrm{F}(2,76)=164.17, \mathrm{p}<.001, \eta_{\mathrm{p}}{ }^{2}=.81$, but no significant main effect of group, $\mathrm{F}$ $(1,38)=0.10, \mathrm{p}>.250, \eta_{\mathrm{p}}{ }^{2}<.01$, or interaction, $\mathrm{F}(2,76)=2.65, \mathrm{p}=.077, \eta_{\mathrm{p}}^{2}=.07$. A priori $t$ tests that collapsed across group found that compared to placebo, drivers reported feeling more intoxicated during the first alcohol session, $\mathrm{t}(38)=14.77, \mathrm{p}<.001, \mathrm{~d}=2.55$, and during the retest session, $\mathrm{t}(38)=14.83, \mathrm{p}<.001, \mathrm{~d}=2.51$.

\section{Discussion}

Results of this study found that DUI offenders and controls showed similar levels of driving impairment following $0.64 \mathrm{~g} / \mathrm{kg}$ alcohol compared to placebo. Despite the similar levels of behavioral impairment, DUI offenders reported less driving impairment under alcohol than did controls. This finding cannot be attributed to group differences in subjective intoxication or $\mathrm{BrAC}$, because the groups were similar on both of these variables. These findings are consistent with the explanation that DUI offenders are less able to perceive how alcohol impairs their driving performance, resulting in an overestimation of driving ability when they are intoxicated. According to self-efficacy theory (Bandura, 1977; Maddux, 1995), this underestimation of impairment should contribute to increased risk of DUI. Results of the alcohol retest support this interpretation of the data. Following feedback indicating that the first alcohol dose impaired driving performance, DUI offenders' perceived impairment was indistinguishable from controls when retested under the same dose of alcohol.

It is important to consider the differential effects of performance feedback between groups. Specifically, although DUI offenders showed a reduction in estimated impairment following performance feedback, controls did not show any change in estimated impairment following the performance feedback. This differential group effect suggests that the performance feedback did not challenge the perceptions of controls to the same extent as DUI offenders. Because controls already perceived themselves to be highly impaired by alcohol, the performance feedback did not challenge their preexisting belief. Among DUI offenders, on 
the other hand, this information was inconsistent with their beliefs about how alcohol influenced their ability to drive, requiring them to alter their perceptions of their ability to drive after drinking.

The tendency of DUI offenders to report lower levels of impairment following alcohol may be associated with their impulsivity. Consistent with previous findings, DUI offenders in this study reported higher levels of impulsivity than did controls. Impulsive individuals overestimate their performance (Brazil et al., 2009; Olvet and Hajcak, 2008), which may explain why DUI offenders overestimated their driving performance. Another possibility is that DUI offenders have inflated self-efficacy with regards to driving after drinking due to their learning history. Each individual instance of impaired driving is unlikely to result in arrest or injury (Beitel et al., 2000). These instances of unpunished impaired driving may inform a maladaptive view that alcohol does not impair their driving performance.

Although we interpret these data to indicate that DUI offenders underestimate their impairment, it is important to note that we are unable to determine relative accuracy of these perceptions based on our data. It is also possible that controls overestimated their level of impairment. Mass communication campaigns aimed at reducing rates of DUI routinely state that alcohol consumption impairs driving performance (De Jong and Hingson, 1998). These messages shape drivers' expectancies, particularly among those with little experience driving after drinking. From a prevention standpoint, however, the relative accuracy of perceived impairment is inconsequential. Any overestimation of impairment is beneficial because it reduces the likelihood that an individual will engage in that behavior (Bandura, 1982).

Findings from the retesting session support the notion that performance feedback could be used to improve intervention efforts with DUI offenders. Intervention programs aimed at reducing DUI are only modestly effective (Wells-Parker et al., 1995). Based on findings of the current study, incorporating individualized feedback into these treatment programs might improve outcomes. Explicit feedback verifying the impairing effects of alcohol on one's driving performance could reduce risk of recidivism as DUI offenders becomes more cognizant of the direct impairing effects of the alcohol on their ability. The possibility that such feedback could improve the efficacy of interventions to reduce rates of recidivism should be addressed in future research. It should also be noted that the current study did not include a group of drivers who received placebo following performance feedback, nor groups who did not receive any performance feedback during the retesting session. These control groups could account for potential alternative explanations for the feedback effect such as the possibility that perceived driving ability of the DUI offenders decreases simply as function of repeated testing.

\subsection{Conclusions}

Results of this study indicate that DUI offenders underestimate alcohol impairment of their ability to drive and identify a strategy for normalizing their perceived impairment. These findings will be important for understanding the high rates of recidivism among DUI offenders and may guide future research into improving treatment outcomes in this group. 


\section{Acknowledgments}

Role of funding sources: This research was supported by the following grants from National Institute on Alcohol Abuse and Alcoholism: R01AA018274 and F31AA022263. The sponsor had no involvement in study design or collection, analysis, or interpretation of data, nor in the writing or submission of this report.

\section{References}

Aston ER, Liguori A. Self-estimation of blood alcohol concentration: A review. Addict. Behav. 2013; 38:1944-1951. http://dx.doi.org/10.1016/j.addbeh.2012.12.017. [PubMed: 23380489]

Bandura A. Self-efficacy: Toward a unifying theory of behavioral change. Psychol. Rev. 1977; 84:191215. http://dx.doi.org/10.1037/0033-295X.84.2.191. [PubMed: 847061]

Bandura A. Self-efficacy mechanism in human agency. Am. Psychol. 1982; 37:122-147. http:// dx.doi.org/10.1037/0003-066X.37.2.122.

Bandura A, Locke EA. Negative self-efficacy and goal effects revisited. J. Appl. Psychol. 2003; 88:8799. http://dx.doi.org/10.1037/0021-9010.88.1.87. [PubMed: 12675397]

Beitel GA, Sharp MC, Glauz WD. Probability of arrest while driving under the influence of alcohol. Inj. Prev. 2000; 6:158-161. http://dx.doi.org/10.1136/ip.6.2.158. [PubMed: 10875678]

Brazil IA, de Bruijn ER, Bulten BH, von Borries AK, van Lankveld JJ, Buitelaar JK, Verkes RJ. Early and late components of error monitoring in violent offenders with psychopathy. Biol. Psychiat. 2009; 65:137-143. http://dx.doi.org/10.1016/j.biopsych.2008.08.011. [PubMed: 18814860]

de Bruijn ER, Grootens KP, Verkes RJ, Buchholz V, Hummelen JW, Hulstijn W. Neural correlates of impulsive responding in borderline personality disorder: ERP evidence for reduced action monitoring. J. Psychiat. Res. 2006; 40:428-437. http://dx.doi.org/10.1016/j.jpsychires.2005.09.004. [PubMed: 16257009]

De Jong W, Hingson R. Strategies to reduce driving under the influence of alcohol. Annu. Rev. Pub. Health. 1998; 19:359-378. http://dx.doi.org/10.1146/annurev.publhealth.19.1.359. [PubMed: 9611624]

Donovan DM, Marlatt GA. Personality subtypes among driving-while-intoxicated offenders: Relationship to drinking behavior and driving risk. J. Consult. Clin. Psychol. 1982; 50:241-249. http://dx.doi.org/10.1037/0022-006X.50.2.241. [PubMed: 7069029]

Donovan DM, Umlauf RL, Salzberg PM. Bad drivers: Identification of a target group for alcoholrelated prevention and early intervention. J. Stud. Alcohol. 1990; 51:136-141. http://dx.doi.org/ 10.15288/jsa.1990.51.136. [PubMed: 2308351]

Fillmore MT, Blackburn JS, Harrison ELR. Acute disinhibiting effects of alcohol as a factor in risky driving behavior. Drug Alcohol Depend. 2008; 95:97-106. http://dx.doi.org/10.1016/j.drugalcdep. 2007.12.018. [PubMed: 18325693]

Fillmore MT, Vogel-Sprott M. Evidence that expectancies mediate behavioral impairment under alcohol. J. Stud. Alcohol. 1996; 57:598-603. http://dx.doi.org/10.15288/jsa.1996.57.598. [PubMed: 8913990]

First, M., Spitzer, R., Williams, J., Gibbon, M. Biometrics Research. New York: New York State Psychiatric Institute; 2002. Structured clinical interview for DSM-IVTR (SCID-I)-research version.

Harrison EL, Fillmore MT. Are bad drivers more impaired by alcohol? Sober driving precision predicts impairment from alcohol in a simulated driving task. Accid. Anal. Prev. 2005; 37:882-889. http:// dx.doi.org/10.1016/j.drugalcdep.2011.01.002. [PubMed: 15907777]

Kaufman, AS., Kaufman, NL. Kaufman Brief Intelligence Test: Manual. Minnesota: American Guidance Service; 2004.

Laude JR, Fillmore MT. Drivers who self-estimate lower blood alcohol concentrations are riskier drivers after drinking. Psychopharmacology. 2016; 233:1387-1394. http://dx.doi.org/10.1007/ s00213-016-4233-x. [PubMed: 26861796]

Maddux, JE. Self-efficacy, adaptation, and adjustment: Theory, research, and application. New York: Plenum Press; 1995. 
Marczinski CA, Harrison EL, Fillmore MT. Effects of alcohol on simulated driving and perceived driving impairment in binge drinkers. Alcohol. Clin. Exp. Res. 2008; 32:1329-1337. http:// dx.doi.org/10.1111/j.1530-0277.2008.00701.x. [PubMed: 18540907]

National Highway Traffic Safety Administration. [accessed 08.15.16] 2014 Traffic safety facts: Alcohol-impaired driving. 2015. https://crashstats.nhtsa.dot.gov/Api/Public/Publication/812231

National Institute on Alcohol Abuse and Alcoholism. [accessed 08.15.16] NIAAA council approves definition of binge drinking. 2004. http://pubs.niaaa.nih.gov/publications/Newsletter/winter2004/ Newsletter_Number3.pdf

Olvet DM, Hajcak G. The error-related negativity (ERN) and psychopathology: Toward an endophenotype. Clin. Psychol. Rev. 2008; 28:1343-1354. http://dx.doi.org/10.1016/j.cpr. 2008.07.003. [PubMed: 18694617]

Patton JH, Stanford MS, Barratt ES. Factor structure of the Barratt impulsiveness scale. J. Clin. Psychol. 1995; 51:768-774. http://dx.doi.org/10.1002/1097-4679(199511)51:6<768::AIDJCLP2270510607>3.0.CO;2-1. [PubMed: 8778124]

Quinn PD, Fromme K. Event-level associations between objective and subjective alcohol intoxication and driving after drinking across the college years. Psychol. Addict. Behav. 2012; 26:384-392. http://dx.doi.org/10.1037/a0024275. [PubMed: 21688876]

Roberts W, Milich R, Fillmore MT. Reduced acute recovery from alcohol impairment in adults with ADHD. Psychopharmacology. 2013; 228:65-74. http://dx.doi.org/0.1007/s00213-013-3016-x. [PubMed: 23430161]

Shaffer HJ, Nelson SE, LaPlante DA, LaBrie RA, Albanese M, Caro G. The epidemiology of psychiatric disorders among repeat DUI offenders accepting a treatment-sentencing option. J. Consult. Clin. Psych. 2007; 75:795-804. http://dx.doi.org/http://dx.doi.org/10.1037/0022-006X. 75.5.795.

Shiels K, Hawk LW Jr. Self-regulation in ADHD: The role of error processing. Clin. Psychol. Rev. 2010; 30:951-961. http://dx.doi.org/10.1016/j.cpr.2010.06.010. [PubMed: 20659781]

Sobell, LC., Sobell, MB. Timeline follow-back: A technique for assessing self-reported alcohol consumption. In: Litten, R., Allen, J., editors. Measuring Alcohol Consumption: Psychosocial and Biochemical Methods. New Jersey: Humana Press; 1992. p. 41-72.

U.S. Department of Justice. [accessed 08.15.2016] Uniform crime reports. 2005. https:// www2.fbi.gov/ucr/05cius/

Van Dyke N, Fillmore MT. Acute effects of alcohol on inhibitory control and simulated driving in DUI offenders. J. Safety Res. 2014a; 49:1-11. http://dx.doi.org/10.1016/j.jsr.2014.02.004.

Van Dyke N, Fillmore MT. Alcohol effects on simulated driving performance and self-perceptions of impairment in DUI offenders. Exp. Clin. Psychopharmacol. 2014b; 22:484-493. http://dx.doi.org/ 10.1037/a0038126. [PubMed: 25347077]

Voas RB, Fell JC. Strengthening impaired-driving enforcement in the United States. Traffic Inj. Prev. 2013; 14:661-670. http://dx.doi.org/10.1080/15389588.2012.754095. [PubMed: 23944649]

Vogel-Sprott, M. Alcohol tolerance and social drinking: Learning the consequences. New York: Guilford Press; 1992.

Watson PE, Watson ID, Batt RD. Prediction of blood-alcohol concentrations in human subjects: Updating the Widmark Equation. J. Stud. Alcohol. 1981; 42:547-556. http://dx.doi.org/10.15288/ jsa.1981.42.547. [PubMed: 7289599]

Weafer J, Camarillo D, Fillmore MT, Milich R, Marczinski CA. Simulated driving performance of adults with ADHD: Comparisons with alcohol intoxication. Exp. Clin. Psychopharmacol. 2008; 16:251-263. http://dx.doi.org/10.1037/1064-1297.16.3.251. [PubMed: 18540785]

Weafer J, Fillmore MT, Milich R. Increased sensitivity to the disinhibiting effects of alcohol in adults with ADHD. Exp. Clin. Psychopharmacol. 2009; 17:113-121. http://dx.doi.org/10.1037/a0015418. [PubMed: 19331488]

Wells-Parker E, Bangert-Drowns R, McMillen R, Williams M. Final results from a meta-analysis of remedial interventions with drink/drive offenders. Addiction. 1995; 90:907-926. [PubMed: 7663313] 


\section{Highlights}

- We evaluated perceived and objective alcohol impairment of driving in DUI offenders

- $\quad$ DUI offenders were equally impaired following alcohol as were controls

- DUI offenders perceived themselves as less impaired than did controls

- $\quad$ Performance feedback corrected this underestimation of impairment in DUI offenders 


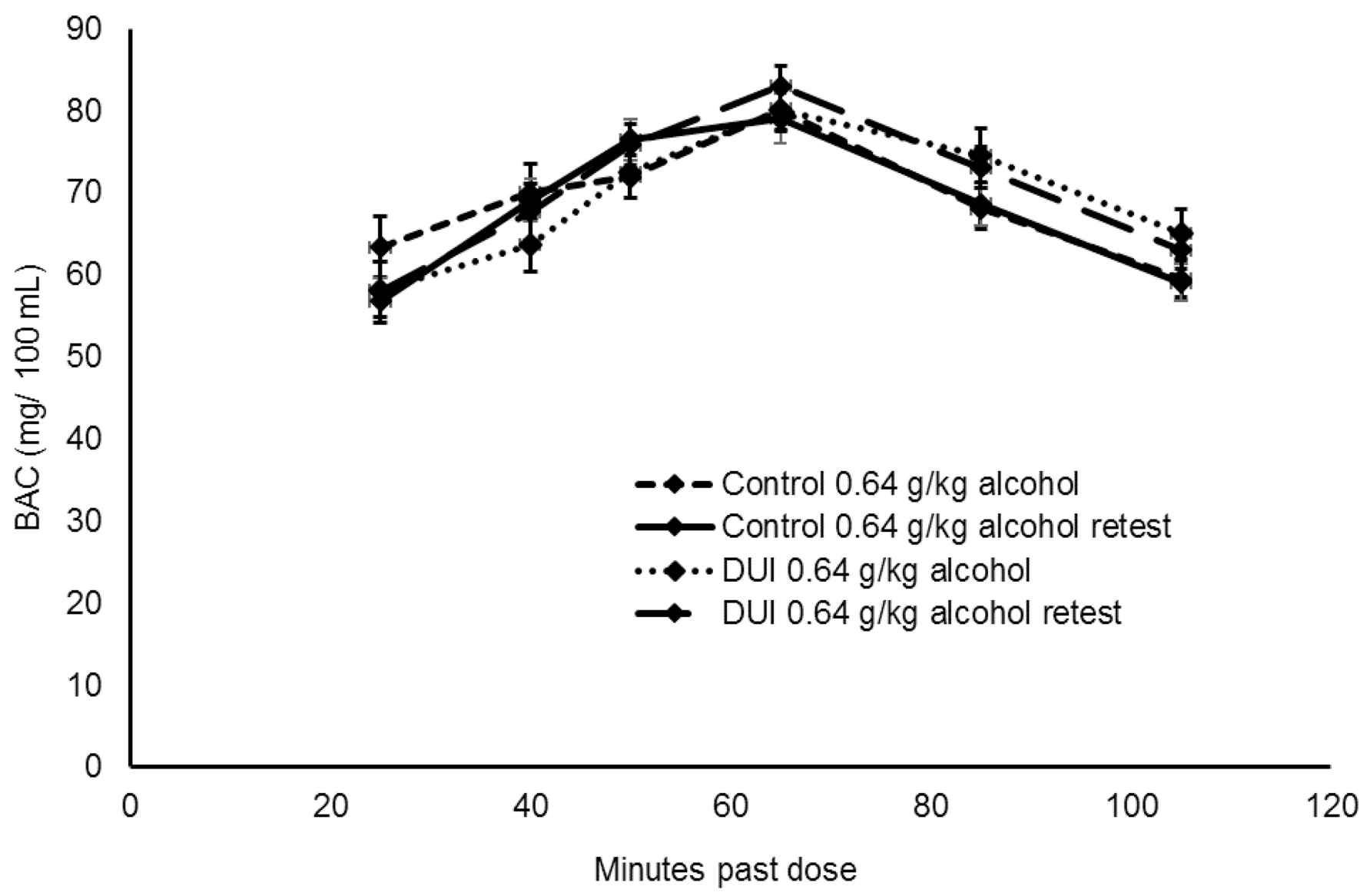

Figure 1.

Mean breath alcohol concentrations displayed separated by group and condition. Capped bars represent SEM. 


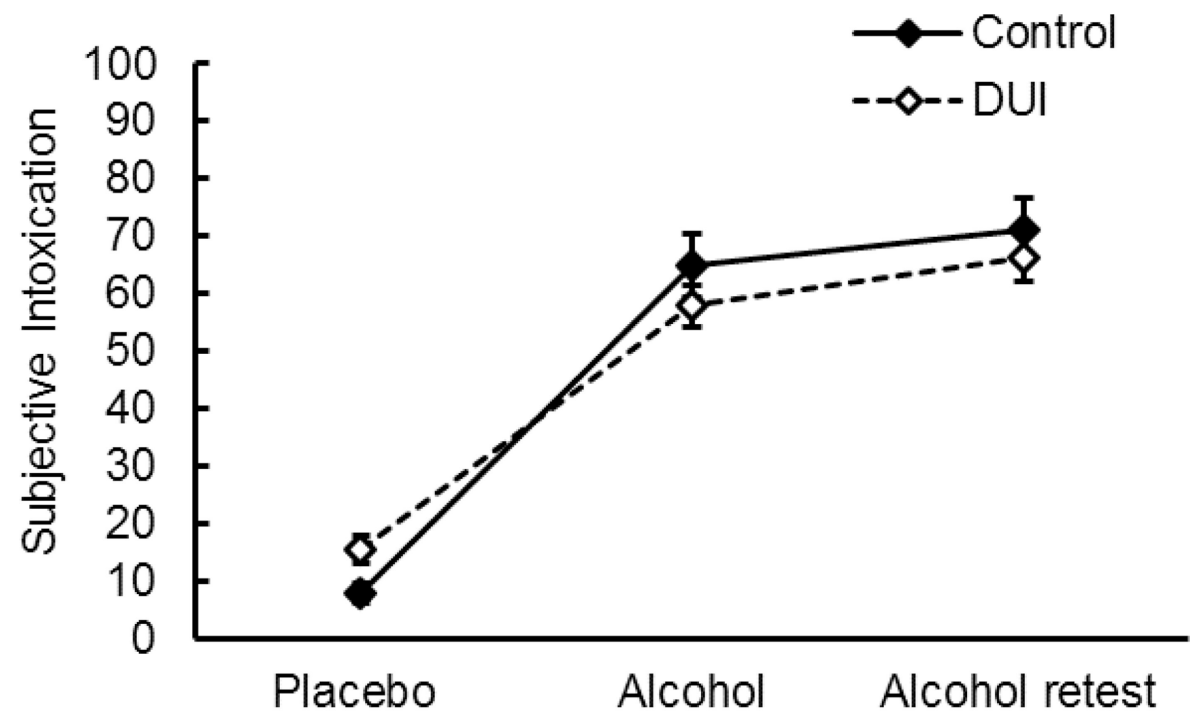

Condition

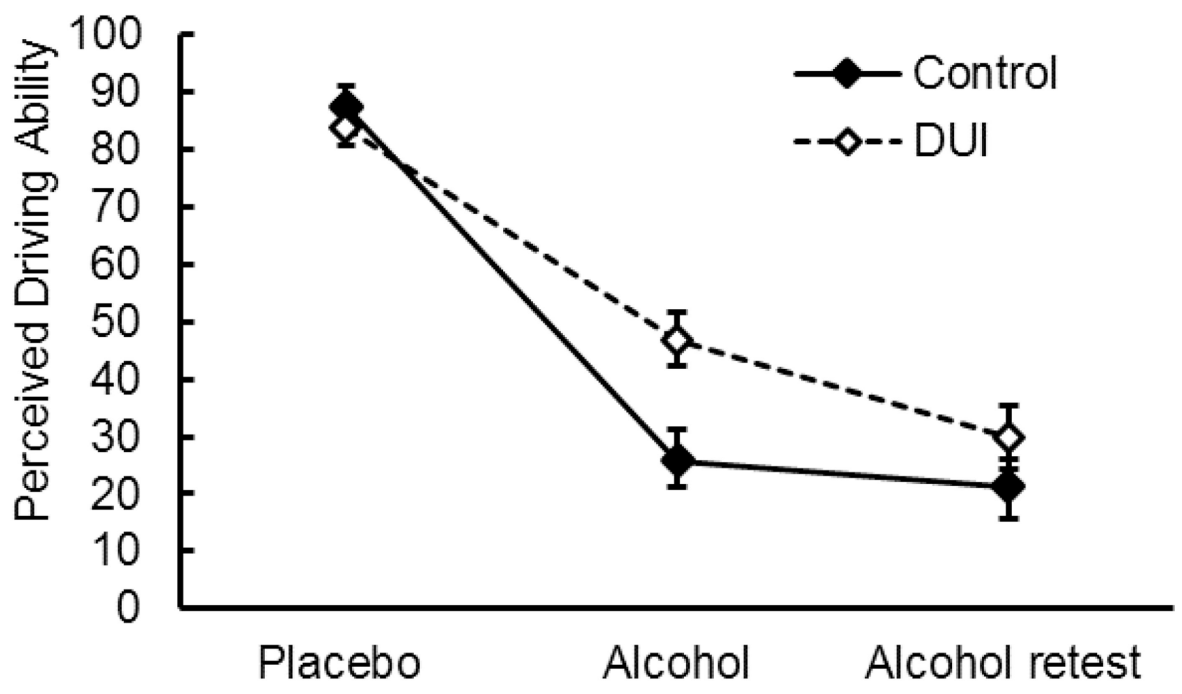

\section{Condition}

Figure 2.

Participants' ratings of subjective intoxication and perceived driving ability the visual analogue scale. Capped bars represent SEM. 


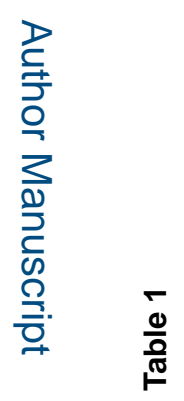

로을

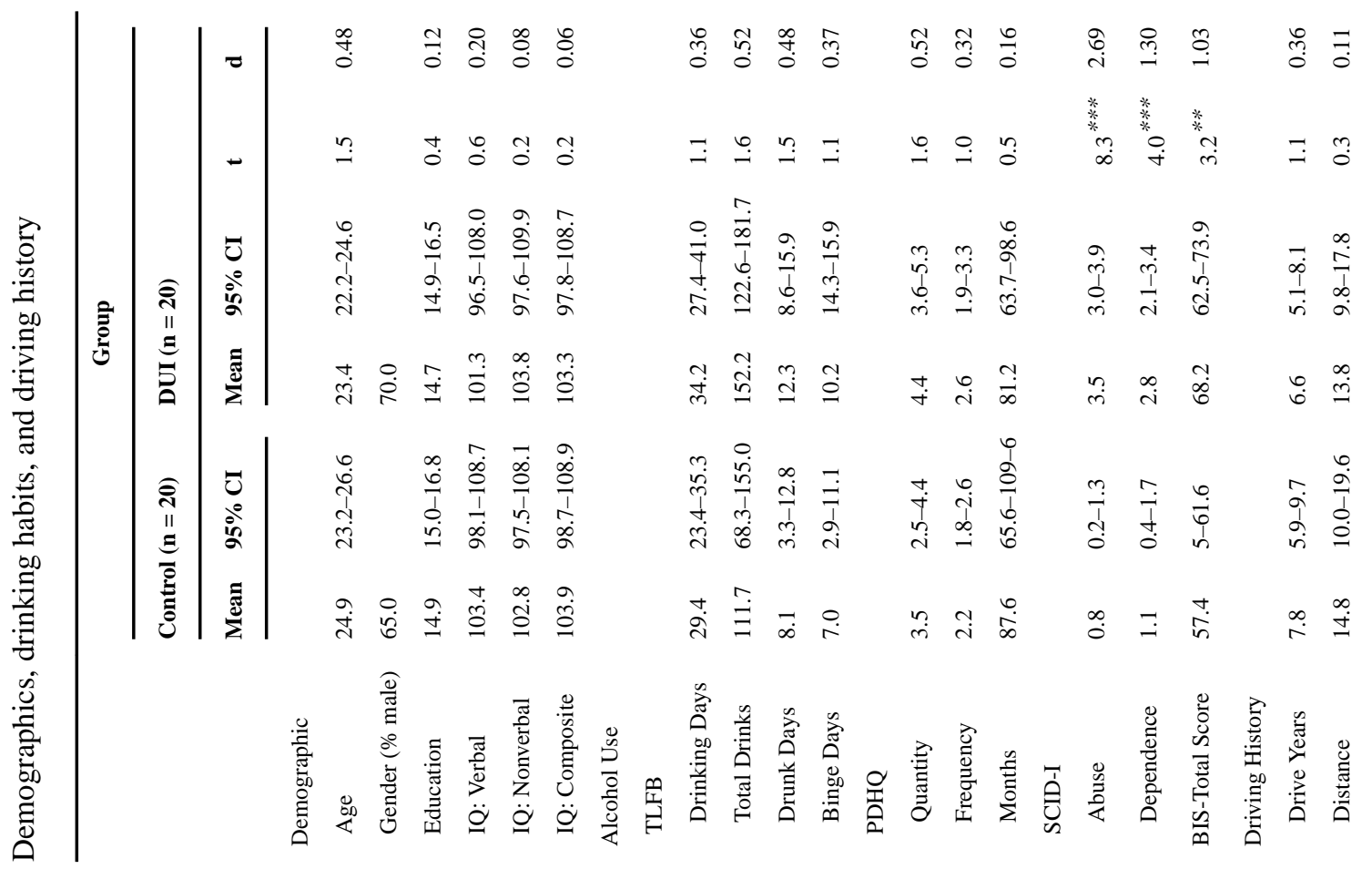

Drug Alcohol Depend. Author manuscript; available in PMC 2018 March 01. 


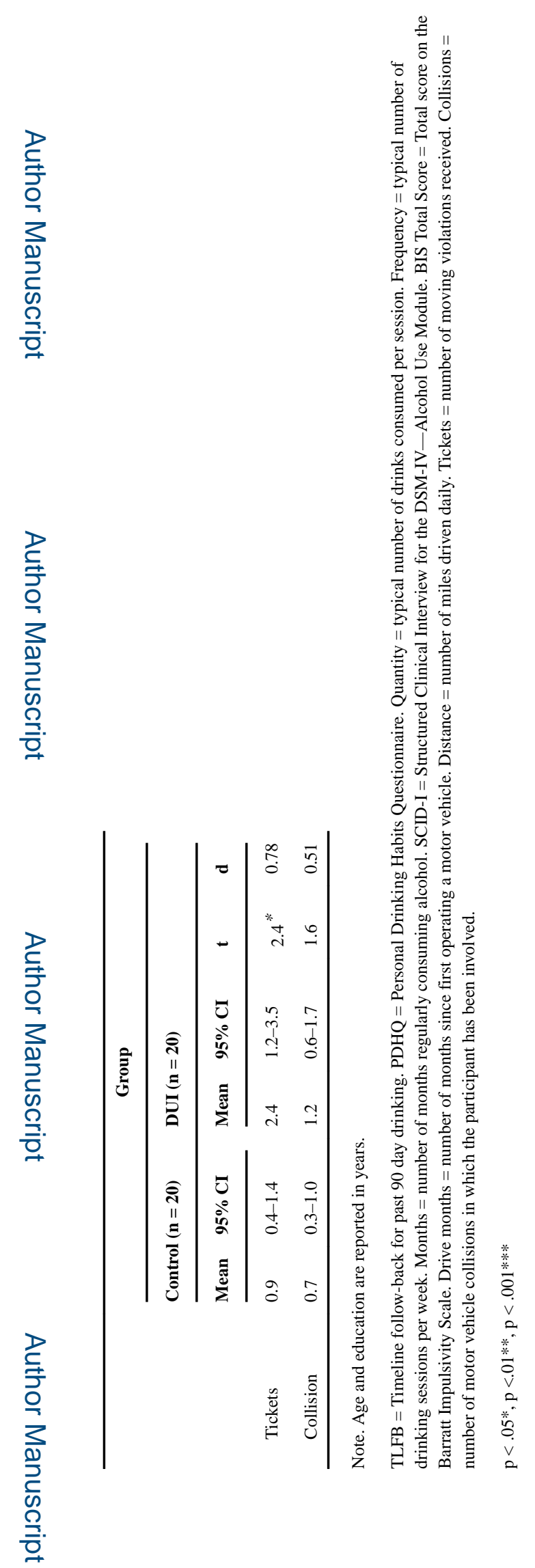

Drug Alcohol Depend. Author manuscript; available in PMC 2018 March 01. 


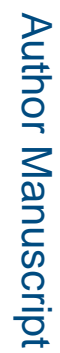

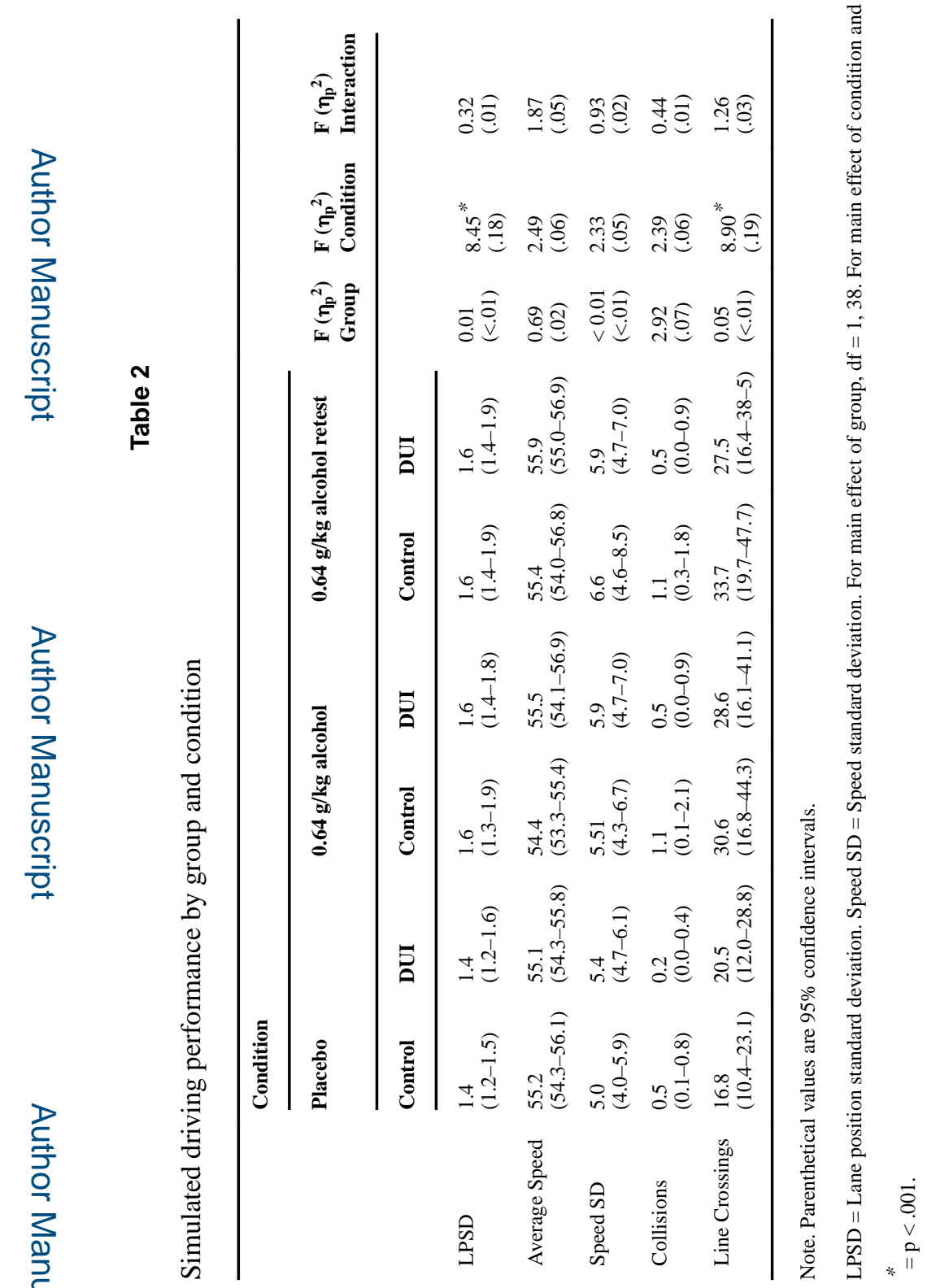

Drug Alcohol Depend. Author manuscript; available in PMC 2018 March 01. 